\title{
Composición y evolución de la informalidad laboral en Colombia durante el periodo 2009-2019
}

\author{
John Ariza* \\ Floro Alexander Retajac**
}

Fecha de recepción: 15 de marzo de 2021

Fecha de aprobación: 8 de junio de 2021

Resumen: En este artículo se estudia la evolución y composición del empleo informal en las principales ciudades de Colombia durante el periodo 2009-2019. Utilizando modelos logit bivariados y multinomiales se examina la probabilidad de ser informal y de pertenecer a las diferentes categorías de empleo informal en función de características sociodemográficas y económicas. Los resultados indican que durante el periodo estudiado la informalidad laboral cayó tanto a nivel nacional como en las principales ciudades del país, excepto para Cúcuta, y que dicha disminución no tuvo ningún patrón específico en términos de composición de los informales. Los informales en Colombia son principalmente hombres con edad promedio de cuarenta años con menos de diez años de escolaridad, que trabajan principalmente en el comercio, la industria y el transporte. En los últimos años tanto la edad promedio como los años de escolaridad de este grupo en general han ido aumentando. Los resultados econométricos sugieren un efecto positivo de la educación sobre la informalidad a nivel local, que podría explicar la reducción en las brechas regionales de informalidad.

Palabras clave: probabilidades, economía informal, educación, economía del trabajo, mercados laborales informales.

Clasificación JEL: C25, E26, J00, J46, H75, I20

Cómo citar

Ariza, J., \& Retajac, F. A. . (2021). Composición y evolución de la informalidad laboral en Colombia durante el período 2009-2019. Apuntes del Cenes, 40(72). Págs. 115 - 148. https://doi.org/10.19053/01203053.v40.n72.2021.12598

\footnotetext{
* Doctor en Economía Aplicada, docente de tiempo completo, Departamento de Economía y Finanzas, Universidad del Tolima, Ibagué, Colombia. Contacto de correspondencia. jfariza@ut.edu.co iD https://orcid.org/0000-0001-5951-7192

** Economista, estudiante de Maestría en Economía, Universidad Nacional de La Plata, La Plata, Argentina. faretajacb@ut.edu.co (iD) https://orcid.org/0000-0003-4397-1002
} 


\title{
Composition and Evolution of the Labor Informality in Colombia During 2009-2019
}

\begin{abstract}
This paper studies the evolution and composition of informal employment in the main cities of Colombia during the period 2009-2019. Using bivariate and multinomial logit models, the probability of being informal and of belonging to the different categories of informal employment based on sociodemographic and economic characteristics is studied. The results indicate that during the period studied, labor informality fell both at the national level and in the main cities of the country, except for Cúcuta, and that such decrease did not have any specific pattern in terms of the composition of the informal workers. Informal workers in Colombia are mainly men with an average age of 40 years with less than 10 years of schooling who work mainly in commerce, industry and transportation. In recent years, both the average age and the years of schooling of this group in general have been increasing. The econometric results suggest a positive effect of education on informality at the local level that could explain the reduction in regional informality gaps.
\end{abstract}

Keywords: Probabilities, informal economy, education, labor economics, informal labor markets. 


\section{INTRODUCCIÓN}

La informalidad laboral es un fenómeno multidimensional y constituye un desafío significativo en la agenda de los gobiernos. El sector informal representa la única fuente de ingresos para un importante contingente de trabajadores en el mundo. Aunque no todos los trabajadores informales realizan actividades precarias o en condiciones riesgosas, generalmente operan al margen de la reglamentación laboral, efectúan trabajos de baja productividad, son mal remunerados y sus ingresos varían constantemente. Estas particularidades impiden que este tipo de trabajadores pueda aportar al sistema de salud y de previsión de ingresos para la vejez; además, los hace especialmente vulnerables a las fluctuaciones del ciclo económico, lo que aumenta la probabilidad de padecer pobreza y precarias condiciones de vida.

De acuerdo con la Organización Internacional del Trabajo (OIT), en América Latina la informalidad, medida como la proporción de ocupados que cotizan o reciben pensión, fue del $53.8 \%$ en 2018 , lo cual representa 130 millones de trabajadores. En el sector urbano la tasa fue del $47.7 \%$ y en el rural del $78.4 \%$. La brecha urbano-rural ha venido aumentando desde 2016 (OIT, 2019). En Colombia, de acuerdo con el Departamento Nacional de Estadística (DANE), la proporción de ocupados informales en las 23 ciudades principales y áreas metropolitanas fue del $47.9 \%$ en 2019. Para el total de las 13 ciudades principales fue del $46.7 \%$ (DANE, 2020).

En este contexto y dada la dimensión de la problemática en el país, mejorar la comprensión de la informalidad es una tarea imprescindible en la medida en que contribuirá directamente a un mejor diagnóstico y al diseño integral de políticas públicas orientadas a combatir este fenómeno. Independientemente de la discusión de la medición de la informalidad a nivel nacional e internacional, el estudio en profundidad de su estructura, composición, evolución $\mathrm{y}$ factores asociados a nivel nacional y local constituye una importante línea de investigación. De acuerdo con lo anterior y dado que los trabajadores 
informales no son iguales entre ellos, es natural preguntarse lo siguiente: ¿Quiénes son los trabajadores informales en Colombia? ¿Cómo ha cambiado su perfil en el tiempo? ¿Qué papel ha jugado la educación en la dinámica de la informalidad?

El presente artículo pretende contribuir en esa línea y tiene como objetivo describir la evolución y composición del empleo informal a nivel nacional y por ciudades. Además, para avanzar sobre la comprensión de los factores sociodemográficos asociados a las diferentes categorías de empleo informal, se estima un modelo logit multinomial que permite observar la manera en que las características de los trabajadores influyen diferencialmente sobre la probabilidad de pertenecer a los componentes de la informalidad. Las estimaciones se hacen utilizando los datos de la Gran Encuesta Integrada de Hogares (GEIH) y a partir de la definición de informalidad del DANE (2009), que permite desagregar los informales entre siete categorías.

Este artículo contribuye al análisis de la evolución y composición de la informalidad a nivel nacional y por ciudades, en un periodo reciente (2009-2019). A diferencia de estudios previos, este trabajo explora en detalle cada componente de la informalidad y presenta evidencia sobre la heterogeneidad en las características de los trabajadores entre cada categoría de la informalidad y entre centros urbanos. Este insumo motiva una discusión más compleja de la informalidad, a través de estudios que exploren esas heterogeneidades y sirvan como referencia en la elaboración de políticas que segmenten entre componentes de la informalidad y entre ciudades. El documento se organiza de la siguiente manera: adicional a esta introducción, en la segunda sección se presenta la revisión de literatura, en la tercera sección se explica la metodología, en la cuarta sección se presentan los resultados y finalmente, en la quinta sección se exponen algunas conclusiones.

\section{REVISIÓN DE LITERATURA}

La definición de informalidad es amplia, dinámica, inconclusa y está en constante debate entre economistas $\mathrm{y}$ académicos interesados en el tema. Para la Organización Internacional del Trabajo (OIT), el trabajo informal comprende "actividades económicas de los trabajadores y las unidades económicas que legalmente no están cubiertas o están insuficientemente cubiertas por las disposiciones institucionales formales" (OIT, 2002, p. 5). Sin embargo, dicho organismo advierte que existen limitaciones para sintetizar la complejidad y el dinamismo del mundo del trabajo informal en una definición precisa, más aún cuando no todos los trabajos informales son necesariamente precarios. 
La literatura especializada identifica insuficiencias en los enfoques teóricos existentes sobre la informalidad laboral, pues estos no satisfacen del todo las precisiones conceptuales y metodológicas que se requieren para su medición (Ferreira, 2014; Yusuff, 2011; Habib-Mintz, 2009). Sin embargo, dado el interés por realizar cálculos del trabajo informal, y de acuerdo con los lineamientos establecidos por la OIT, se han considerado, generalmente, tres criterios para cuantificar este fenómeno: el primero está relacionado con empleos que están por fuera del marco regulatorio del trabajo, el segundo hace referencia al tipo y tamaño de la unidad productiva, y el tercero tiene que ver con la categoría ocupacional del trabajador (Hussmanns, 2004; Bernal, 2009). Las mediciones de informalidad se alinean a algún criterio o a una conjunción entre estos y el interés por profundizar en aspectos como la calidad del trabajo.

En Colombia la medición de la informalidad es realizada por el DANE, el cual define como trabajador informal a i) los empleados particulares y los obreros que trabajan en establecimientos, negocios o empresas que ocupen hasta cinco personas en todas sus agencias y sucursales, incluyendo al patrono y/o socio; ii) los trabajadores familiares sin remuneración; iii) los trabajadores sin remuneración en empresas o negocios de otros hogares; iv) los empleados domésticos; v) los jornaleros o peones; vi) los trabajadores por cuenta propia que laboran en establecimientos hasta cinco personas (excepto los independientes profesionales) y vii) los patrones o empleadores en empresas de cinco trabajadores o menos (DANE, 2009)1.

Una vez hechas estas precisiones conceptuales, a continuación, se presentarán los determinantes y las características más distintivas que la literatura disponible identifica sobre el trabajo informal en Colombia. Esta aproximación permitirá entender quiénes son los informales, en qué se ocupan y cuáles son los elementos que caracterizan las diferentes categorías ocupacionales que conforman la informalidad. Adicionalmente, de acuerdo con la literatura económica, se discutirán los factores institucionales y económicos que inciden sobre la informalidad. Por último, se abordará un conjunto de trabajos que presentan heterogeneidades en el nivel de informalidad entre ciudades en Colombia. En estos estudios se identifican los centros urbanos más afectados y las características asociadas a las diferencias territoriales.

Con relación a los determinantes de la informalidad, diversos estudios identifican factores sociodemográficos como

$1 \quad$ La medición de informalidad del DANE enfrenta críticas. Para Ferreira (2014), el DANE mide solo la proporción de empleo en el sector informal, no considera características y calidad del empleo. El autor encuentra que hay heterogeneidad en el nivel de precariedad laboral entre las categorías que conforman los informales. Guataquí et al. (2010) afirman que el tamaño de la empresa no es un instrumento técnico riguroso para detectar la informalidad. El tamaño está vinculado más cercanamente con la estructura productiva de la empresa que con las características del puesto de trabajo. Una discusión amplia sobre definición y medición de la informalidad se encuentra en el Manual estadístico sobre el sector informal y el empleo informal (OIT, 2013). 
el sexo, la edad, el nivel educativo, el ingreso y el origen étnico. Mediante un modelo de selección binaria y usando la GEIH, Guataquí et al. (2010) estimaron los determinantes de la informalidad y encontraron que las mujeres tienen mayor riesgo de trabajar en la informalidad en Colombia. Este grupo tiene una probabilidad de ser informal entre $12 \mathrm{y}$ 8,4 puntos porcentuales mayor que la de los hombres. En edades avanzadas, la informalidad en las mujeres sobrepasa en diez puntos porcentuales la de los hombres. Baquero et al. (2018), con base en la GEIH, identifican que las mujeres tienen una incidencia de la informalidad cuatro puntos porcentuales mayor que la de los hombres.

Adicionalmente, Ramírez (2015), con base en los datos de la GEIH, indica que entre 2008 y 2015 el $54 \%$ de las mujeres ocupadas eran informales. Por su parte, Bernal (2009), al estimar un modelo logit, encuentra que las mujeres tienen una probabilidad de ser informales dos puntos porcentuales superior a la de los hombres. Salinas et al. (2012), al valuar un modelo tipo probit con base en la Encuesta Continua de Hogares (ECH) y al considerar todos los componentes de la informalidad (asalariados, cuenta propia, empleados domésticos, etc.), no encuentran una diferencia estadísticamente significativa en la probabilidad de informalidad entre hombres y mujeres; pero al restringir las estimaciones para asalariados y cuenta propia únicamente, obtienen que las mujeres asalariadas tienen mayor probabilidad de ser informales, y entre los cuenta propia esa probabilidad es menor que la de los hombres.

Por otro lado, la literatura económica identifica la edad como un determinante de la informalidad. Con base en la ECH, The World Bank (2010) observa que en Colombia la edad tiene una relación en forma de $U$ con la probabilidad de ser un trabajador informal. Para 2010 alrededor del $97 \%$ de los trabajadores entre 15 y 18 años que conformaban la población en edad de trabajar (PET) eran informales y el porcentaje fue de $79 \%$ entre las personas de 45 años. Los trabajadores más jóvenes inician su trayectoria laboral en la informalidad y con el tiempo van ingresando al mercado formal. Bernal (2009) estima que trabajadores entre 25 y 44 años tienen una probabilidad de ser informal 2,3 puntos porcentuales mayor que la de trabajadores mayores de 44 años. Arango et al. (2020) estiman un modelo probit y encuentran que la probabilidad de ser informal incrementa monótonamente con la edad. Las personas de 51 a 65 años tienen una probabilidad de ser informal un $33 \%$ mayor que los trabajadores entre 18 y 25 años.

El trabajo de Guataquí et al. (2010) encuentra un patrón similar; la informalidad decrece con la edad, con efectos particulares en las personas más jóvenes y al final del ciclo de vida. Entre los componentes de la informalidad, Salinas et al. (2012) estiman que para los cuenta propia la probabilidad de 
informalidad aumenta con la edad, pero cada vez a una tasa menor. Este hallazgo está en consonancia con el trabajo de The World Bank (2010), donde se indica que las personas de mayor edad entre la informalidad son principalmente trabajadores cuenta propia. Por su parte, la probabilidad de informalidad para los asalariados decrece con la edad y presentan las tasas más altas de transición desde el sector formal al informal.

Otro determinante preponderante en la literatura de la informalidad es el nivel educativo. Diversos estudios indican que en Colombia la informalidad está más directamente relacionada con la educación que con cualquier otra característica sociodemográfica. La mayoría de los trabajadores con educación secundaria o menos es informal. Las personas con más años de educación presentan la tasa más alta de migración desde la informalidad hacia el sector formal. De acuerdo con Ramírez (2015), en el periodo 20082015, la tasa de informalidad fue, en promedio, del $75 \%$ entre las personas sin ningún nivel educativo y del $48 \%$ entre las personas con educación secundaria únicamente. No obstante, debido a la magnitud de la informalidad en Colombia, una proporción considerable de trabajadores con relativamente alto nivel educativo está en la informalidad (The World Bank, 2010).

Las estimaciones de Salinas et al. (2012) a través de un modelo probit señalan que la probabilidad de encon- trarse en la informalidad disminuye a mayor nivel educativo; puntualmente, la educación secundaria reduce la probabilidad de informalidad 20,7 puntos porcentuales y la educación superior 65,4 puntos porcentuales. Las estimaciones de Guataquí et al. (2010) indican que la educación secundaria reduce la probabilidad de ser informal en 30 puntos porcentuales y la educación superior en 74 puntos porcentuales. Por su parte, Bernal (2007) considera que los trabajadores presentan 11,5 y 55,5 puntos porcentuales menor probabilidad de ser informales al tener educación primaria completa y universitaria completa, respectivamente.

En cualquier caso, el nivel educativo y la informalidad guardan una relación no lineal; la reducción en el riesgo de informalidad frente al cambio marginal en los años de educación es mucho más grande cuanto mayor sea el nivel educativo que tiene la persona. Curiosamente, Salinas et al. (2012) encuentran que, para los asalariados la probabilidad de informalidad decrece con la educación, mientras que para los cuenta propia esa probabilidad se incrementa con la educación. Como explicación argumentan que los informales menos educados tienden a trabajar como asalariados y los informales con mayor cualificación trabajan mayoritariamente por cuenta propia.

En otra dirección, la literatura económica identifica que el desplazamiento forzoso o violento reduce las posibili- 
dades de incorporarse al sector formal. Cuando las víctimas de estos sucesos migran hacia otros lugares con bajos niveles educativos, limitada posesión de activos y habilidades no demandas en el lugar de destino, terminan empleándose en actividades informales, las cuales continúan desarrollando a largo plazo. $\mathrm{Su}$ situación los lleva a estar dispuestos a trabajar por un salario muy bajo. Romero (2013) estima un modelo logit ordenado con los datos de la Encuesta de Calidad de Vida (ECV) para evaluar la correlación entre el desplazamiento violento hacia los centros urbanos en Colombia y la probabilidad de pertenecer al sector informal. Sus resultados indican que el desplazamiento violento aumenta en un $5 \%$ la probabilidad de trabajar en el sector informal y el mayor tiempo de asentamiento en el lugar de destino no contribuye significativamente a mejorar el riesgo de emplearse en el sector informal.

Otro determinante de la informalidad es la etnicidad. Las poblaciones indígenas, pese a representar una pequeña parte de la fuerza laboral en Colombia, están sobrerepresentadas en el sector informal. El $45 \%$ de los trabajadores indígenas corresponde a trabajadores por cuenta propia informales; mientras que esa tasa es del $41 \%$ entre afrocolombianos y del $35 \%$ entre mestizos. Solo el $7 \%$ de los trabajadores indígenas logra emplearse en el sector formal y en comparación con otros grupos enfrenta el doble de probabilidad de realizar trabajos no remunerados. Por su parte, el $25 \%$ de los afrocolombianos accede a trabajos formales (The World Bank, 2010). Bernal (2009), al estimar un modelo logit, encuentra que los indígenas y afrocolombianos tienen una probabilidad de ser informales un 5.5 y $2.3 \%$ mayor con relación al resto de la población, respectivamente.

Adicionalmente, los informales se caracterizan por percibir ingresos inferiores que los trabajadores del sector formal, pero la brecha no es constante a lo largo de la distribución de ingresos. Como señala Galvis (2013), la diferencia es mayor en la cola izquierda de la distribución y se va reduciendo al acercarse a la media; alrededor del $97 \%$ de los trabajadores que pertenecen al quintil de ingreso más bajo están en la informalidad. En el tiempo ese porcentaje se ha reducido levemente, ubicándose, de acuerdo con Baquero et al. (2018), en un $87.5 \%$ en 2017. Mediante un modelo probit y usando la GEIH, Galvis (2013) encuentra que la probabilidad de ser informal decrece con el nivel de ingreso, pero hay diferencias en el tamaño de los efectos marginales entre quintiles de ingreso; por ejemplo, los trabajadores del cuarto quintil tienen un $2 \%$ menor probabilidad de ser informales respecto a los trabajadores del primer quintil, pero ese efecto marginal es $1.7 \%$ para el último quintil. Es decir que, al comparar trabajadores formales e informales de los deciles de ingreso más altos, la brecha es menos importante que en el resto de la distribución. De acuerdo con Galvis 
(2013), ese patrón podría ser un incentivo a trabajadores de altos ingresos para permanecer en la informalidad. Si bien la informalidad declina con el nivel de ingreso, cerca de la mitad de los trabajadores más ricos son informales.

Como resultado de la heterogeneidad entre las categorías ocupacionales que conforman la informalidad, existe alta volatilidad en el nivel de ingreso; ciertas categorías (los asalariados) tienen niveles de ingreso significativamente inferiores que los de los trabajadores formales, mientras que otras (patrones) experimentan remuneraciones más altas y similares a las del sector formal (García, 2017). Por otro lado, entre los informales, las personas de mayor edad tienen ingresos más bajos; los trabajadores familiares sin remuneración tienen entre 12 y 17 años; los asalariados oscilan entre los 18 y 45, y los patrones son mayoritariamente personas con una edad superior (Galvis, 2013; Bernal, 2009; The World Bank, 2010; Bonet et al., 2016). Correlacionado con el bajo nivel de ingreso, Salinas et al. (2012) encuentran que las actividades en el sector informal se caracterizan por ser de baja productividad y con bajos niveles de cualificación.

Esas particularidades hacen que los informales trabajen generalmente en empresas pequeñas. Galvis (2013) estima que la probabilidad de informalidad es un $1 \%$ mayor en empresas con dos a cinco empleados en comparación con las unipersonales. Pero para establecimientos con seis o más empleados la probabilidad de informalidad se reduce considerablemente, pues es un $22 \%$ menor para empresa con seis a diez empleados, un $38 \%$ menor para empresas con once a diecinueve empleados, y un $64 \%$ menor para empresas con más de treinta empleados. No obstante, Bernal (2009) encuentra que el $17 \%$ de empleados formales trabajan en empresas con 10 trabajadores o menos, y cerca del $24 \%$ de los empleados informales trabajan en empresas con más de diez trabajadores. Lo que evidencia que no necesariamente todo el trabajo informal se concentra en pequeñas unidades productivas.

Además, los informales trabajan generalmente en los sectores comercio, restaurantes, manufactura, construcción, hotelería y turismo. La incidencia de la informalidad es menor en los sectores financiero, servicios, inmobiliario, administración pública, minas y canteras, y educación (Galvis, 2013; Bonet et al., 2016; Bernal, 2009; Ramírez, 2015). De acuerdo con las estimaciones de Guataquí et al. (2010), trabajar en el sector comercio y construcción eleva la probabilidad de ser informal un 26 y $13 \%$, respectivamente. En cambio, emplearse en el sector servicios y minas y canteras reduce la probabilidad un 50 y $10 \%$, respectivamente. Estos resultados están parcialmente en consonancia con las estimaciones de Bernal (2009), quien encuentra que trabajar en los sectores de construcción y agricultura aumenta en un 6 y $5 \%$ la probabilidad 
de informalidad, respectivamente. La autora no observa un efecto significativo para los sectores manufactura, servicios y transporte.

La literatura señala a los cuenta propia como el grupo mayoritario entre los que integran la informalidad. En ese grupo la informalidad alcanza el $90.3 \%$. Los trabajadores cuenta propia son, principalmente, personas mayores de 45 años, tienen 17 puntos porcentuales más probabilidad de ser informales que los empleados, poseen bajo nivel educativo (alrededor del $60 \%$ de las personas sin ningún nivel educativo son cuenta propia) y el $61 \%$ son hombres. El $67 \%$ de los informales cuenta propia ganan menos que el salario mínimo por mes. Solamente el $10 \%$ de este tipo de trabajadores ganan más de cinco salarios mínimos (The World Bank, 2010; Bernal, 2009). El trabajo de Galvis et al. (2019) indica que los ocupados en empleos públicos tienen la tasa de informalidad más baja y los empleados domésticos y por cuenta propia tienen una tasa de informalidad del 93 y $91 \%$, respectivamente.

Respecto a los factores económicos e institucionales que inciden sobre el nivel de informalidad, algunos autores han identificado que ese fenómeno está estrechamente relacionado con el comportamiento del ciclo económico. En las fases de recesión el número de informales incrementa (principalmente los cuenta propia) a la par que se reduce la cantidad de asalariados en el sector formal. La incapacidad de la economía formal para generar puestos de trabajo acrecienta la informalidad (Uribe et al., 2006; Quejada et al., 2014; Salcedo et al., 2020). Otros autores han identificado que la probabilidad de ser informal aumenta con la duración del desempleo y eso lleva a que este fenómeno sea una de las causas principales de la informalidad (Berrío \& Bran, 2017; Quejada et al., 2014; Galvis, 2013).

También ligado al mercado laboral, Mora (2007) señala que la exclusión generada por la segmentación del mercado de trabajo es una de las principales causas de la informalidad en Colombia y que aun los trabajadores más educados se ven afectados. Existen restricciones de movilidad entre el sector informal y formal que impiden que los trabajadores informales mejoren su estatus laboral (Mora, 2017; Uribe et al., 2006; Bernal, 2009; The World Bank, 2010). Esa segmentación permanece en el tiempo y, como indican Canavire et al. (2016), la baja movilidad puede explicar la persistencia de la informalidad. El número de trabajadores que migran hacia el sector informal supera el desplazamiento que hay desde este último hacia la formalidad.

Ciertos factores institucionales y normativos también se han identificado como causantes de la informalidad en Colombia (García, 2008). El trabajo de Hamann y Mejía (2011) argumenta que el marco legal e institucional en el país constituye un obstáculo para la 
formalización empresarial. A partir de microsimulaciones de equilibrio parcial estático y dinámico encuentran que las reducciones en los costos (impuestos sobre las utilidades y salarios) asociados a operar en el sector formal, permiten que el tamaño relativo de este sector tenga un crecimiento significativo; reducciones en el costo de crear una empresa formal tiene un impacto exponencial sobre la informalidad. De acuerdo con estos últimos autores, si Colombia tuviera los costos de creación de empresa al nivel del promedio de América Latina, el sector formal crecería un $33 \%$. Si se cierra la brecha salarial entre el sector formal e informal y se reducen los impuestos a la formalidad, se reduciría 14 puntos porcentuales la informalidad en el país.

Mediante un modelo de equilibrio general, Mejía y Posada (2007) encuentran que el cambio técnico en el sector formal reduce la informalidad y que el aumento de impuestos induce a la informalidad. Con una carga impositiva del $22 \%$ al ingreso del sector formal se genera una tasa de informalidad natural de $18.1 \%$. Usando el método de diferencias en diferencias y los datos de la GEIH, Fernández y Villar (2018) evaluaron el impacto de la reducción del pago de las contribuciones de nómina del $29.5 \%$ al $16 \%$ en Colombia en 2014 y encontraron que el cambio en la carga impositiva disminuyó la informalidad entre 4,3 y 6,8 puntos porcentuales en las trece principales ciudades. Herrera et al. (2019), al evaluar la misma reforma con una estrategia de triple diferencia y los datos de la GEIH, estiman que la reducción de los pagos de nómina incrementó en un $2.9 \%$ el salario de trabajadores en ciudades con nivel medio de informalidad. Además, aumentó 2,5 y 4,1 puntos porcentuales la proporción de trabajadores que ganan al menos un salario mínimo en ciudades con nivel medio y alto de informalidad, respectivamente.

El tercer y último foco en este apartado tiene que ver con las diferencias en el nivel de informalidad entre ciudades. Diversos autores identifican que las ciudades con mayor informalidad se localizan por fuera del corredor de actividad económica de Colombia que integran Bogotá, Medellín, Bucaramanga y Cali (Guataquí et al. 2010; Arango \& Flórez, 2017; Galvis, 2013; Bonet et al., 2016). No obstante, esto no se cumple en Barranquilla, ciudad que presenta un nivel de informalidad por debajo del promedio nacional. Los centros urbanos con mayor nivel de informalidad a lo largo de los años han sido Cúcuta, Quibdó, Sincelejo, Riohacha, Santa Marta y Florencia. Por su parte, Cali, Pereira y Tunja registran una tasa de informalidad cercana al promedio nacional. Las ciudades con menor incidencia son Bogotá, Medellín, Manizales y Tunja (Ariza \& Montes, 2017; Arango \& Flórez, 2017; Galvis, 2013; Bonet et al, 2016). 
A través de un modelo probit, Galvis (2013) estima que, por ejemplo, los ocupados en Quibdó, Valledupar y Cúcuta tienen un $12 \%, 9 \%$ y $7 \%$ más probabilidad de ser informales respecto a los ocupados en Bogotá. En cambio, esa probabilidad es un $3 \%, 16 \%, 14 \%$ y $6 \%$ menor en Bucaramanga, Medellín, Armenia y Pereira, respectivamente. Con base en los datos de la GEIH, Galvis y Pérez (2015) encuentran que en la región Pacífica colombiana dos de cada tres trabajadores son informales. Los departamentos de la región tienen mayor nivel de informalidad que el promedio nacional. Por su parte, Galvis et al. (2019) detectan que en el Caribe colombiano la informalidad, aunque se ha reducido, continúa siendo elevada y alrededor de diez puntos porcentuales por encima del promedio nacional, pese a que en las principales ciudades el nivel de desempleo haya mejorado. En esa región los autores identifican brechas muy amplias entre trabajadores con diferentes niveles educativos.

Sobre las causas de las diferencias en el nivel de informalidad entre ciudades, García (2008) argumenta que cada centro urbano presenta características económicas, sociales y productivas particulares; además, juega un papel importante la cercanía a otras ciudades y el grado de desarrollo industrial. Para Galvis (2013), el salario mínimo no es un instrumento que elimine las brechas salariales entre formales e informales, de hecho, refuerza el nivel de infor- malidad al representar un costo muy elevado para vincular trabajadores en el sector formal.

En una dirección similar, Arango y Flórez (2021) argumentan que el anormal nivel del salario mínimo es el factor más importante detrás del alto nivel de informalidad en Colombia. Usando el método generalizado de momentos con un enfoque de datos de panel, estiman que el incremento de un punto porcentual del salario mínimo aumenta en 0,16 puntos porcentuales la tasa de informalidad. El efecto es heterogéneo entre ciudades; por ejemplo, es de 0,850 , 0,658 y 0,415 puntos porcentuales para Villavicencio, Ibagué y Montería, respectivamente, y de 0,102 y 0,228 para Quibdó y Bogotá. Las diferencias entre centros urbanos pueden explicarse por disparidades de la productividad laboral y porque el crecimiento en el salario mínimo no se ha correspondido con el aumento de la productividad.

En el mismo sentido, Arango et al. (2020) dividen la población dentro de cada ciudad por sexo, edad y nivel educativo, estiman un probit con un enfoque de datos de panel y muestran que el incremento de un punto porcentual de la razón del salario mínimo y el salario del percentil 70 de la distribución de salarios, incrementa la probabilidad de informalidad en 0,21 puntos porcentuales. Este efecto es mayor en las ciudades con más informalidad. Estos resultados concuerdan con las estimaciones de Arango y 
Flórez (2017), quienes utilizando un enfoque de datos de panel con variables instrumentales y con la información de la GEIH, hallan que un incremento de un punto porcentual del salario mínimo como proporción al salario mediano, aumenta 0,18 puntos porcentuales la informalidad. Estos autores también descubren que el tamaño del efecto varía entre ciudades (por ejemplo, 0,83 en Popayán, 0,35 en Florencia y 0,08 en Montería).

De la revisión anterior se puede concluir que los trabajadores informales en Colombia son principalmente personas con bajo nivel educativo y bajos ingresos. Las mujeres, los indígenas y las víctimas de desplazamiento son particularmente vulnerables. Los informales son en su mayoría cuenta propia y se emplean en empresas pequeñas que desarrollan actividades en los sectores de construcción, hotelería, comercio y manufacturero. Por otro lado, la literatura indica que la informalidad se reduce con mayor crecimiento económico, productividad y una normativa tributaria más flexible. Finalmente, diversos estudios evidencian que en Colombia la informalidad se distribuye heterogéneamente entre las ciudades. Los centros urbanos de la costa Caribe y del Pacífico son los más afectados, mientras que en las ciudades más grandes se presenta una menor incidencia.

\section{METODOLOGÍA}

La metodología del presente artículo se compone de tres partes. En primer lugar, se estudian los componentes de la informalidad laboral a nivel nacional y para las 23 principales ciudades del país de acuerdo con la definición de informalidad del DANE (2009) que engloba las características de los empleos de los trabajadores. Basados en esta definición, se establecen las siguientes categorías de empleo informal para el presente trabajo:

- Asalariados informales: empleados particulares y obreros que laboran en establecimientos, negocios o empresas que ocupen hasta cinco personas en todas sus agencias y sucursales

- Cuenta propia informales: trabajadores por cuenta propia que laboran en establecimientos hasta cinco personas, excepto los independientes profesionales.

- Trabajadores familiares: trabajadores familiares sin remuneración.

- Trabajadores en empresas: trabajadores sin remuneración en empresas o negocios de otros hogares.

- Empleados domésticos: trabajadores en el servicio doméstico.

- Jornaleros o peones: trabadores que se desempeñan como jornaleros o peones.

- Patrones informales: patrones o empleadores en empresas de cinco trabajadores o menos. 
Para el análisis de composición y evolución del empleo informal se construyen dichas categorías a nivel nacional y por ciudades para el periodo que va de 2009 a 2019. La fuente de datos es la Gran Encuesta Integrada de Hogares, que es la encuesta oficial para reportar los indicadores laborales en el país. Esta encuesta tiene una cobertura de 23 ciudades y áreas metropolitanas. En segundo lugar, y de conformidad con lo presentado en la sección de revisión de literatura, se estudian las diferentes categorías de trabajadores informales a partir de las características personales de los trabajadores en términos de género, edad y nivel educativo en consonancia con lo planteado por The World Bank (2010), Guataquí et al. (2010) y Ramírez (2015). Se consideran también variables relacionadas con características del hogar como tamaño, composición y percepción de rentas no laborales. Igualmente, se tiene en cuenta la rama de actividad económica en la que labora el individuo.

Finalmente, y con el propósito de brindar evidencia empírica sobre los factores asociados a la probabilidad de ser informal, se estiman modelos logit bivariados y multinomiales para los años 2009 y 2019. En el caso de los modelos multinomiales, estos permiten estudiar la correlación entre las características sociodemográficas de los trabajadores y la condición de informalidad en un contexto en el que esta variable dependiente tiene más de dos categorías y la información del individuo se tiene solo para la categoría elegida y no para las otras categorías. En términos formales, el modelo logit multinomial parte de la ecuación (1)

$$
p_{i j}=\frac{\exp \left(\boldsymbol{x}_{i}^{\prime} \beta_{j}\right)}{\sum_{l=1}^{m} \exp \left(\boldsymbol{x}_{i}^{\prime} \beta_{l}\right)}, j=1, \ldots, m
$$

En donde $p_{i j}$ es la probabilidad de que el individuo i escoja la alternativa $j$ condicional a un conjunto de variables explicativas, $\boldsymbol{x}_{i}$ es la matriz de variables explicativas y j es el número de categorías que van de 1 a $m$. En este modelo, la probabilidad $p_{i j}$ se encuentra entre 0 y 1 y $\sum_{j=1}^{m}=1$. Cameron y Trivedi (2010) manifiestan que para asegurar la identificación del modelo $\beta_{j}$, se hace cero para una de las categorías y los coeficientes estimados se interpretan con relación a esta categoría denominada categoría base. En el contexto del presente trabajo, el número de categorías de empleo informal es igual a siete y la categoría base es el servicio doméstico. Por tanto, se estimarán coeficientes para cada una de las variables explicativas para seis categorías que se interpretarán en términos de la categoría de servicio doméstico.

Ahora bien, dado que, como en el caso del modelo logit bivariado, es necesario transformar la ecuación (1) para obtener una expresión lineal en los parámetros $\beta_{j}$ en la que la variable dependiente queda finalmente expresada en términos del logaritmo del ratio de 
probabilidades, se estimará el promedio de los efectos marginales de cada una de las variables explicativas. En la Tabla 1 se presentan los detalles de las variables consideradas.

Tabla 1. Variables en los modelos econométricos

\begin{tabular}{ll}
\hline \multicolumn{1}{c}{ Variables } & \multicolumn{1}{c}{ Descripción } \\
\hline Dependiente en el modelo logit bivariado & $\begin{array}{l}\text { Ser trabajador informal de acuerdo } \\
\text { con la definición del DANE }\end{array}$ \\
\hline Informalidad & \\
\hline Dependiente en el modelo logit multinomial & \\
\hline $\begin{array}{l}\text { Asalariado informal } \\
\text { Cuenta propia informal } \\
\text { Trabajador familiar informal } \\
\text { Trabajador en empresa informal }\end{array}$ & Ser trabajador informal de acuerdo \\
Empleado doméstico informal (categoría base) & con la definición del DANE \\
Jornalero o peón informal & \\
Patrón informal & \\
\hline Explicativas & \\
\hline Mujer & Ser mujer \\
Edad & Años cumplidos \\
Años educación & Años de educación \\
Tamaño del hogar & Número de personas en el hogar \\
Menores & Número de menores de seis años en el hogar \\
Hogar unipersonal & Pertenecer a un hogar uniparental \\
Rentas no laborales & Percibir rentas no laborales en el hogar \\
Ramas de actividad económica & Rama de actividad en la que trabaja \\
Ciudad & Ciudad en la que reside \\
\hline
\end{tabular}

Fuente: elaboración propia con base en la GEIH.

\section{RESULTADOS}

\section{Evolución y composición de la infor- malidad en Colombia}

En la Figura 1 se presenta la evolución de la informalidad laboral en Colombia durante el periodo 2009-2019. Como se observa, la informalidad laboral en el país ha caído tanto en el ámbito urbano como rural. En el 2009, más del $65 \%$ de los trabajadores a nivel nacional y más de la mitad en las zonas urbanas se encontraban en situación de informalidad. Para el 2019, la tasa a nivel nacional rondaba el $60 \%$, mientras que para las zonas urbanas se acercaba al $47 \%$. La caída en las tasas de informalidad no tiene una explicación única. Al parecer, es un efecto combinado entre algunas políticas locales tendientes a incrementar la formalidad, un escenario macroeconómico que favoreció la generación de empleo y, hasta cierto periodo, factores de oferta relativamente estables. 


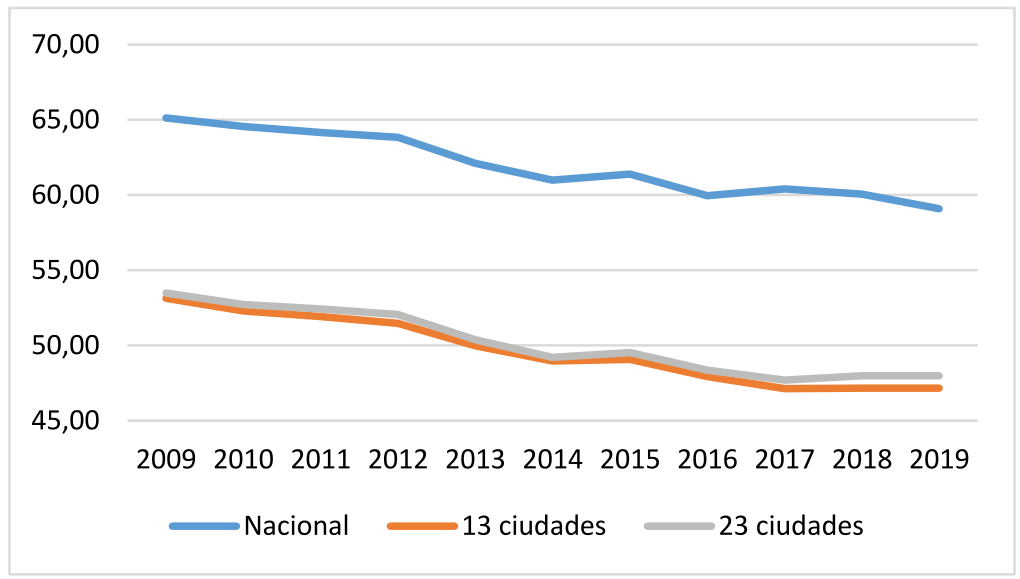

Figura 1. Evolución de la informalidad laboral en Colombia.

Fuente: cálculos de los autores con base en la GEIH.

En la Tabla 2 se presentan algunas características generales de los ocupados y de los informales para las 23 ciudades y áreas metropolitanas en Colombia. Se observa en la tabla que para el 2009, el $45 \%$ de los ocupados en el país eran mujeres. La edad promedio de los ocupados era de 38 años y tenían 9,9 años promedio de educación. Los sectores que más concentraban el empleo fueron el comercio, la industria, el transporte y las actividades inmobiliarias. En el caso de los informales, el
$47 \%$ eran mujeres, tenían cerca de 40 años de edad y 8,0 años promedio de educación. Por sectores económicos, el comercio (33\%), la industria (13\%), el transporte (12\%), la construcción (7\%) y las actividades inmobiliarias (7\%) concentran la mayor parte de los informales. Por tanto, en 2009 el perfil de los trabajadores informales era el siguiente: principalmente mujeres, con edades mayores que el promedio de los ocupados y niveles de educación menores que el promedio de los ocupados.

Tabla 2. Características generales de los ocupados y de los informales en Colombia 2009 y 2019. Promedio de las variables

\begin{tabular}{ccccc}
\hline & \multicolumn{2}{c}{$\mathbf{2 0 0 9}$} & \multicolumn{2}{c}{$\mathbf{2 0 1 9}$} \\
\hline Variable & Total ocupados & Informales & Total ocupados & Informales \\
Mujer & 0,45 & 0,47 & 0,46 & 0,47 \\
Edad & 37,9 & 39,85 & 39,54 & 42,31 \\
Años educación & 9,90 & 8,05 & 11,07 & 9,11 \\
Agricultura & 0,01 & 0,01 & 0,07 & 0,00 \\
Minas & 0,02 & 0,00 & 0,00 & 0.00 \\
Industria & 0,17 & 0,13 & 0,14 & 0,12 \\
Gas, agua & 0,00 & 0,00 & 0,00 & 0,00
\end{tabular}


Continuación Tabla 2

\begin{tabular}{ccccc}
\hline & \multicolumn{2}{c}{$\mathbf{2 0 0 9}$} & \multicolumn{2}{c}{$\mathbf{2 0 1 9}$} \\
\hline Construcción & 0,05 & 0,07 & 0,07 & 0,08 \\
Comercio & 0,24 & 0,33 & 0,22 & 0,31 \\
Hoteles & 0,05 & 0,07 & 0,07 & 0,10 \\
Transporte & 0,10 & 0,12 & 0,09 & 0,11 \\
Financiero & 0,01 & 0,00 & 0,02 & 0,00 \\
Inmobiliarias & 0,09 & 0,07 & 0,10 & 0,07 \\
Servicios & 0,05 & 0,06 & 0,06 & 0,07 \\
Otros & 0,17 & 0,10 & 0,17 & 0,10 \\
\hline
\end{tabular}

Fuente: cálculo de los autores con base en la GEIH.

Para el 2019, la proporción de mujeres en el total de ocupados aumentó y se mantuvo constante en el caso de los informales. De igual manera, la edad y los años promedio de educación aumentaron tanto para el total de ocupados como para los informales. En el caso de la edad, el incremento fue levemente mayor para los informales que para los ocupados. Por sectores económicos, el comercio (31\%), la industria (12\%) y el transporte (11\%) siguen concentrando la mayor parte de los informales. Los hoteles $(10 \%)$, la construcción (8\%) y los servicios (7\%) aumentaron su participación en los ocupados informales en $3 \%, 1 \%$ y $1 \%$, respectivamente.

En el ámbito local, en la Figura 2 se presenta la evolución de las tasas de informalidad para las 23 ciudades y áreas metropolitanas más importantes del país consideradas en la GEIH durante el periodo estudiado. Esta figura muestra que existe una gran disparidad entre ciudades con relación a sus niveles de informalidad. Para el 2009, las tasas de informalidad más altas se presentaban en Sincelejo, Montería y Riohacha, en donde el porcentaje de trabajadores informales superaba el $69 \%$. Este resultado concuerda con lo reportado por Galvis y Pérez (2015) y Galvis et al. (2019).

En contraste, en ciudades como Bogotá, Manizales y Medellín dicho porcentaje no alcanzaba a la mitad de sus trabajadores en el mismo año. Un hecho importante por resaltar con relación a esta disparidad regional es que, durante el periodo analizado, la informalidad cayó más, en general, para las ciudades que presentaron los niveles más altos en 2009 que para ciudades que iniciaron con menores tasas (ver Figura 3). La caída en Sincelejo y Montería es mayor en términos absolutos, que la caída en Bogotá o Medellín. Esto implica alguna mejora en la brecha de informalidad entre ciudades, aunque la brecha sigue siendo amplia. 


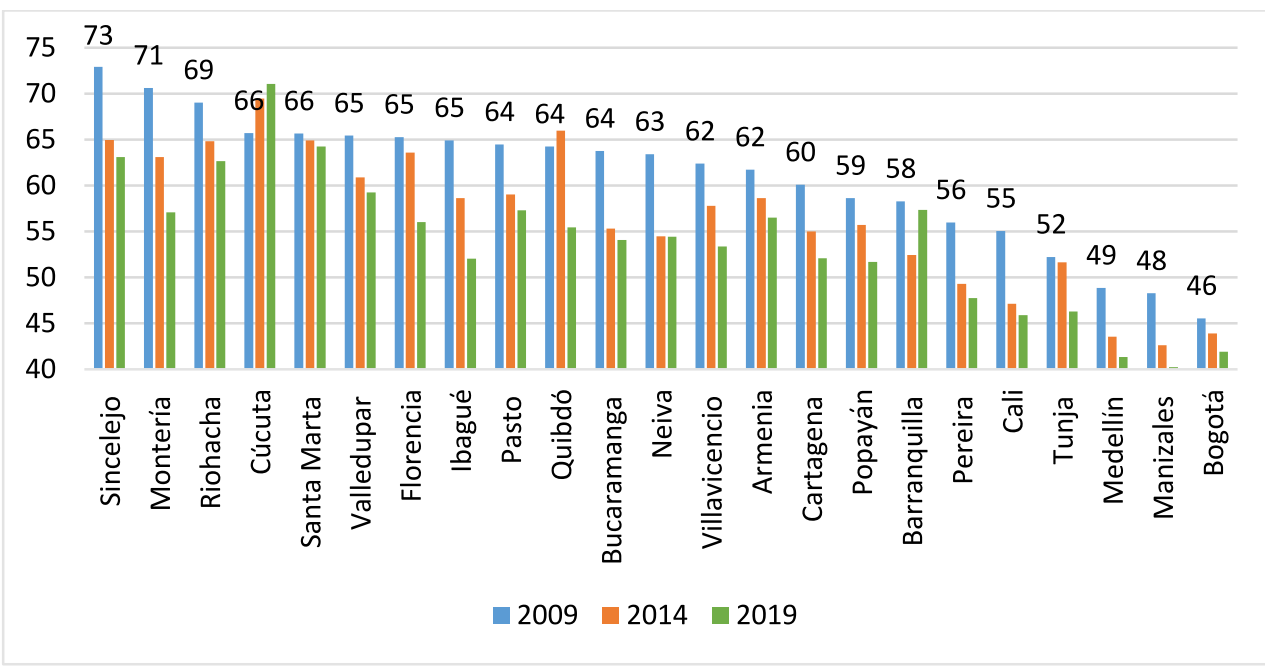

Figura 2. Informalidad laboral por ciudades en Colombia: 2009, 2014 y 2019.

Fuente: cálculos de los autores con base en la GEIH.

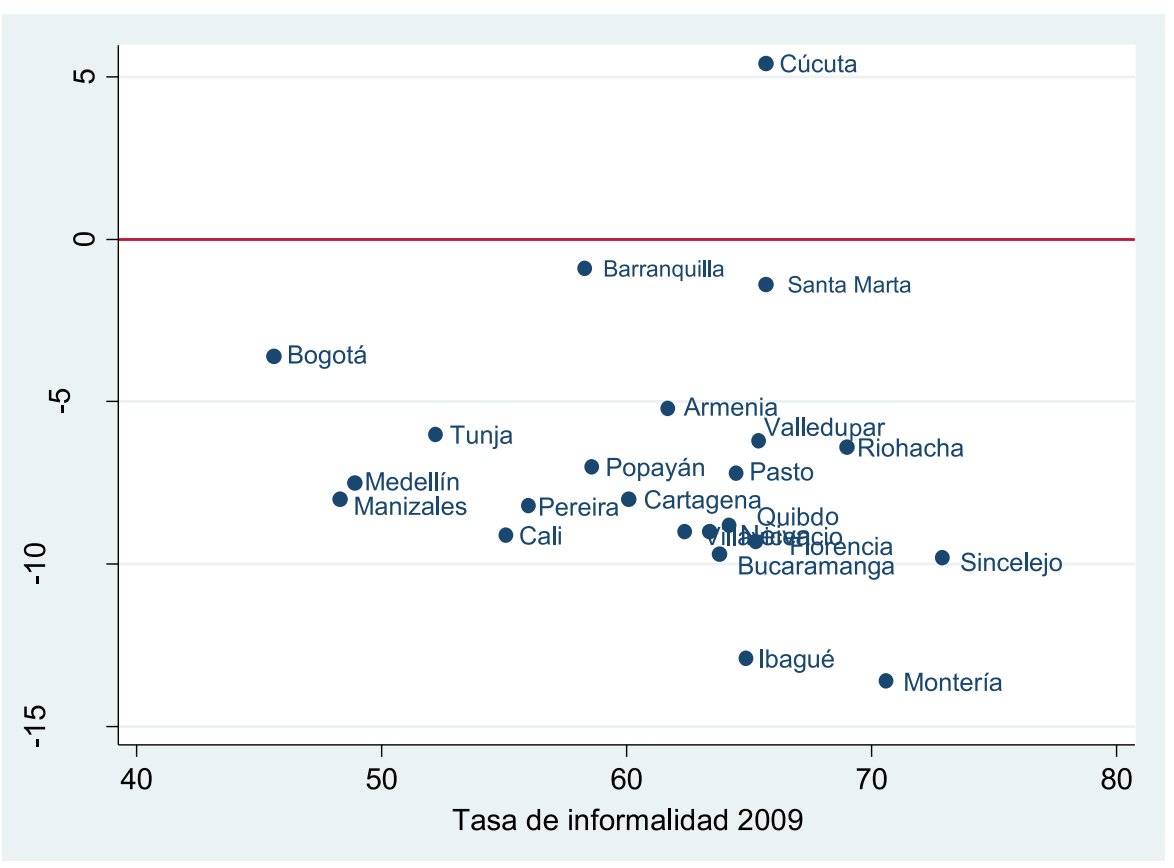

Figura 3. Variación en la tasa de informalidad por ciudades 2009-2019.

Fuente: cálculos de los autores con base en la GEIH. 
Con relación a la composición de la informalidad laboral en el país, en la Figura 4 se presentan las categorías que definen el trabajo informal según el DANE. Como se observa, los informales cuenta propia son el principal grupo de trabajadores informales a nivel nacional. Cerca del $60 \%$ del empleo informal se encuentra en esta categoría. Por otro lado, los informales asalariados y los trabajadores familiares sin remuneración le siguen en orden de importancia con una participación del $15 \%$ y el $6.6 \%$ del total, respectivamente. Los patrones, empleados domésticos y jornaleros o peones presentan participaciones entre el $5.5 \%$ y el $5.9 \%$ del total.
Una de las principales características de la evolución del empleo informal en términos de su composición es la poca variabilidad del grupo de informales con empleo por cuenta propia y asalariados, por un lado, y la leve reducción en las categorías con menor participación en el total de informales, por otro. La Figura 4 muestra claramente que la composición del empleo informal no ha sufrido grandes cambios a nivel nacional durante el periodo 2009-2019. La caída en el grado de informalidad a nivel nacional y la poca variabilidad en las grandes categorías de la informalidad a nivel nacional podrían explicarse porque los cambios en el ámbito de la ciudad se anulan al agregarse los indicadores.

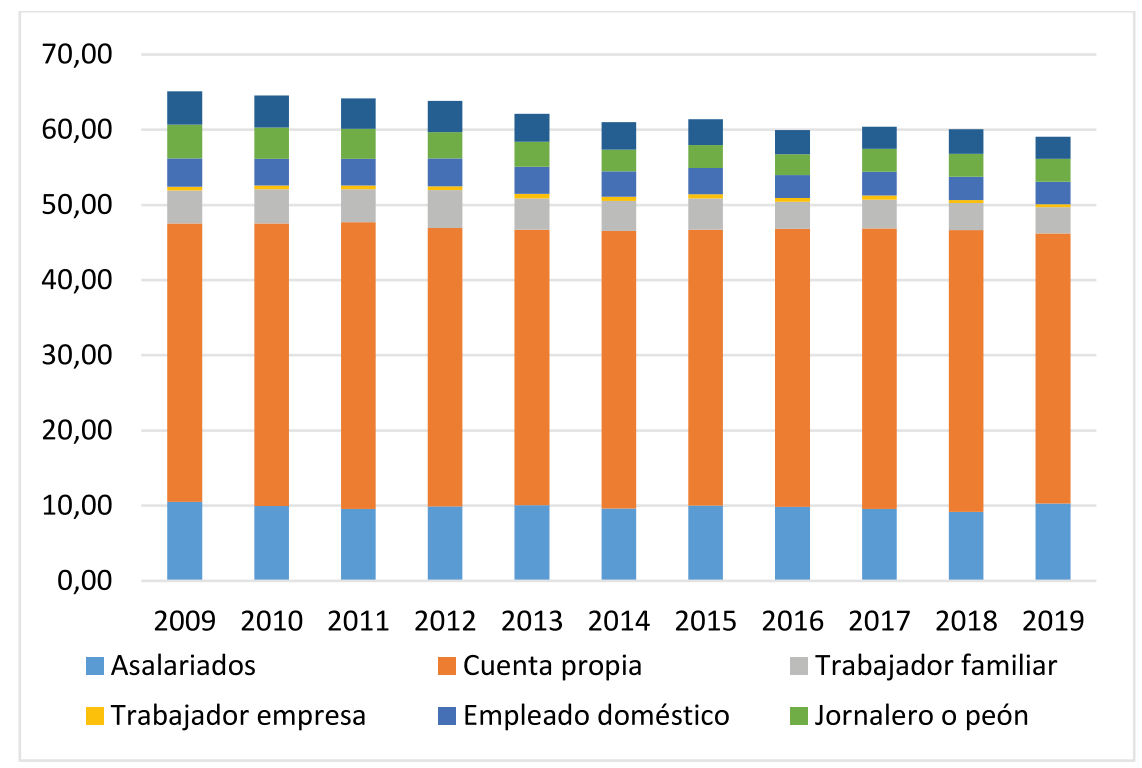

Figura 4. Composición de la informalidad laboral en Colombia. Nacional.

Fuente: cálculos de los autores con base en la GEIH. 
Para analizar el comportamiento en las ciudades, en la Figura 5 se presenta la composición del empleo informal en 2009. Como se observa, en el ámbito local existen diferencias marcadas en términos de composición de los informales entre ciudades con altas y bajas tasas de informalidad. Por ejemplo, en ciudades con altos niveles de informalidad como Sincelejo, el grupo de trabajadores por cuenta propia tiene una gran participación, mientras que en ciudades con bajos niveles como Bogotá, dicha participación es menor.

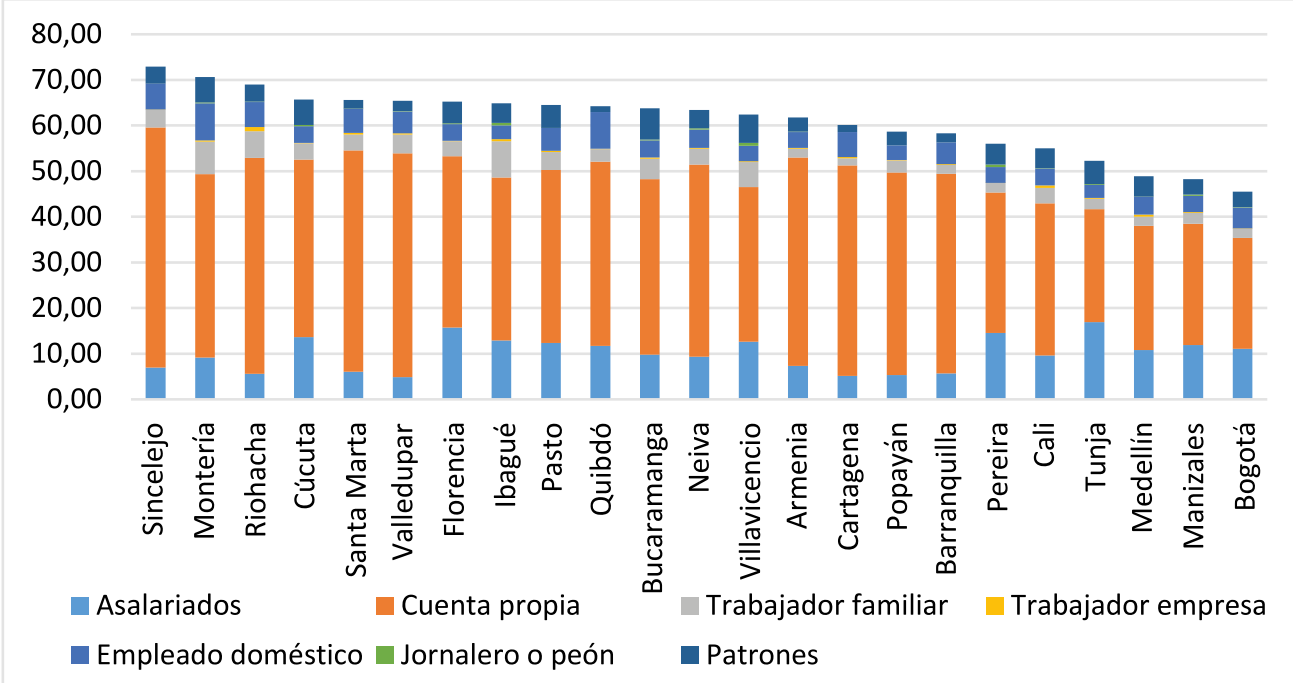

Figura 5. Composición de la informalidad laboral en Colombia 2009.

Fuente: cálculos de los autores con base en la GEIH.

Con relación al cambio en la composición de los trabajadores informales, en la Figura 6 se presenta la variación absoluta en las tasas de informalidad en la ciudad. En esta figura se observa que la informalidad cae para todas las ciudades excepto para Cúcuta, en donde la caída de la informalidad en los asalariados y empleados domésticos se compensa por un gran incremento de la informalidad por cuenta propia. A diferencia de este patrón en Cúcuta, para un conjunto de ciudades la caída en la tasa de informalidad entre el 2009 y el 2019 se da principalmente por una disminución de los informales cuenta propia. Se destaca el caso de Sincelejo, Florencia, Cartagena y Popayán, en donde la caída en valor absoluto es superior a los siete puntos porcentuales. En otros casos, la caída está más asociada a asalariados, empleados domésticos y trabajadores familiares. Este es el caso de Montería, Riohacha, Ibagué, Quibdó, Villavicencio, Pereira, Tunja y Bogotá. 


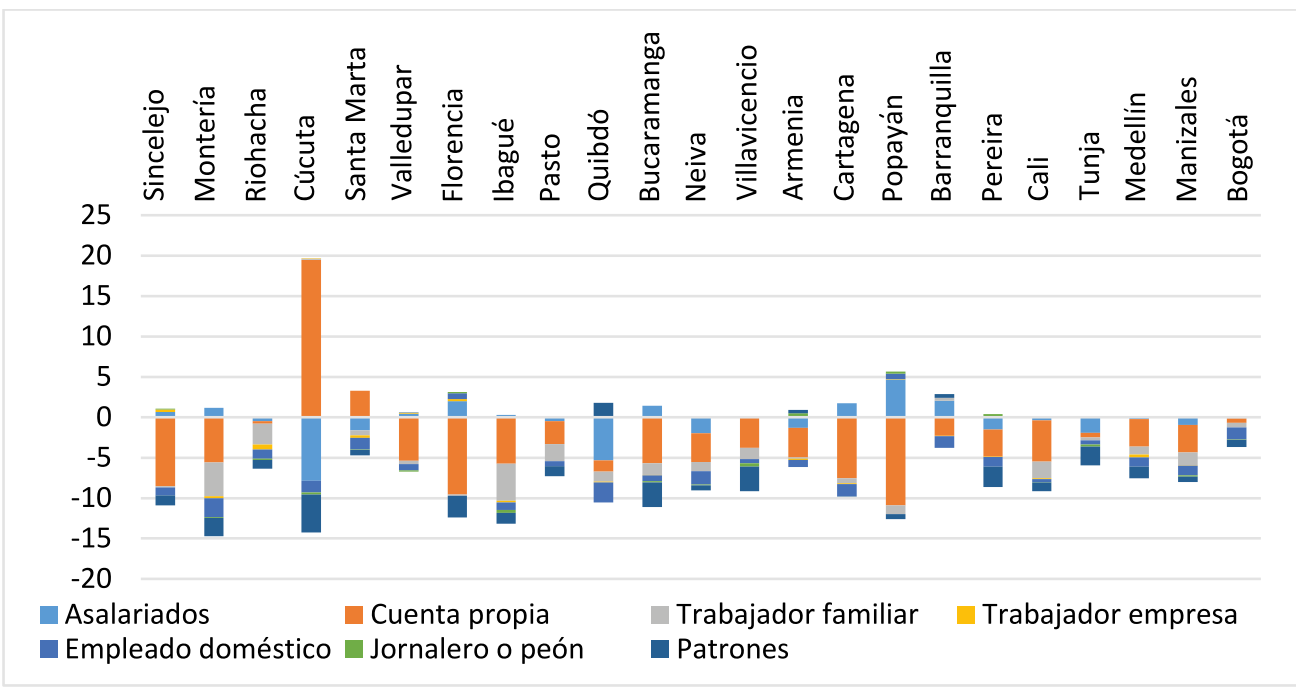

Figura 6. Composición de la informalidad laboral en Colombia 2009.

Fuente: cálculos de los autores con base en la GEIH.

La principal conclusión es que la caída en la informalidad es heterogénea en las ciudades y no exhibe un patrón definido con relación al comportamiento del empleo informal cuenta propia o asalariado. Este resultado plantea la necesidad de considerar algunos factores sociodemográficos asociados a la condición de informalidad con el propósito de comprender mejor los cambios. A continuación se presentan algunas estadísticas descriptivas de los trabajadores informales por posición ocupacional relativas al género, la edad, la escolaridad, el tamaño del hogar y la percepción de rentas por parte de los hogares.

\section{Características de los informales por posición ocupacional}

Considerando la posición ocupacional, en la Tabla 3 se presentan los promedios de algunas características sociodemográficas de los informales en Colombia para el 2009 y el 2019. Como se observa, para el 2009 la distribución de la informalidad por sexo está bien marcada en las diferentes categorías. En el caso de asalariados, cuenta propia, jornaleros y patrones, más del $57 \%$ de los informales son hombres. En contraste, las categorías de trabajadores familiares, trabajadores en empresas y servicio doméstico están mayoritariamente conformadas por mujeres. Este resultado está en consonancia con lo planteado por Guataquí et al. (2010) y Ramírez (2015). 
En cuanto a la edad, los patrones, jornaleros y cuenta propia tenían en promedio más de 42 años. En lo relativo a la educación, los patrones, trabajadores en empresas y asalariados presentaban en promedio los mayores años de escolaridad dentro del grupo de los informales. Los trabajadores informales en empresas y los patrones informales pertenecían a hogares con menos de cuatro integrantes, y más del $29 \%$ de estos dos grupos percibían algún ingreso no laboral en el hogar.

Tabla 3. Características generales de los trabajadores informales por posición ocupacional. Promedio de las variables

\begin{tabular}{|c|c|c|c|c|c|c|c|}
\hline 2009 & $\begin{array}{l}0 \\
0 \\
\frac{0}{0} \\
-\frac{\pi}{2} \\
\frac{\pi}{\pi} \\
\frac{0}{4} \\
\frac{10}{4}\end{array}$ & $\begin{array}{l}\frac{\pi}{0} \\
\frac{0}{0} \\
\frac{2}{2} \\
\frac{\pi}{\pi} \\
\frac{0}{0} \\
\frac{J}{J}\end{array}$ & 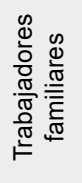 & 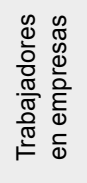 & 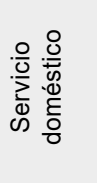 & 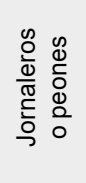 & 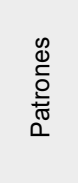 \\
\hline Mujer & 0,40 & 0,43 & 0,68 & 0,63 & 0,94 & 0,01 & 0,27 \\
\hline Edad & 33,62 & 42,09 & 33,13 & 36,37 & 38,70 & 42,15 & 44,01 \\
\hline Educación & 8,82 & 7,71 & 8,51 & 9,77 & 6,52 & 5,38 & 10,21 \\
\hline Tamaño del hogar & 4,32 & 4,31 & 4,49 & 3,80 & 4,47 & 5,01 & 3,97 \\
\hline Rentas & 0,18 & 0,20 & 0,21 & 0,34 & 0,21 & 0,16 & 0,29 \\
\hline \multicolumn{8}{|l|}{2019} \\
\hline Mujer & 0,43 & 0,43 & 0,70 & 0,70 & 0,96 & 0,04 & 0,31 \\
\hline Edad & 35,64 & 44,37 & 37,30 & 37,43 & 44,93 & 39,06 & 44,99 \\
\hline Educación & 10,04 & 8,75 & 9,29 & 10,89 & 7,78 & 5,81 & 10,94 \\
\hline Tamaño del hogar & 4,13 & 4,12 & 4,35 & 3,74 & 4,13 & 4,55 & 3,67 \\
\hline Rentas & 0,16 & 0,20 & 0,22 & 0,25 & 0,22 & 0,06 & 0,25 \\
\hline
\end{tabular}

Fuente: cálculos de los autores con base en la GEIH.

Durante el periodo estudiado, en todos los casos, a excepción de cuenta propia, las mujeres aumentaron su participación en las diferentes categorías de la informalidad. En trabajadores en empresas sin remuneración y patrones, el aumento fue de seis y tres puntos porcentuales respectivamente. En el caso de la edad, se destaca el aumento de la edad promedio del grupo de empleados domésticos con seis años y el de trabajadores familiares con cua- tro años, respectivamente. Los cuenta propia aumentaron dos años de edad en promedio. En el caso de la educación, los años de escolaridad aumentaron para todas las categorías, aunque con diferencias importantes entre ellas. Los mayores incrementos se dieron en las categorías de empleados domésticos, asalariados, trabajadores en empresas y cuenta propia, respectivamente. Todos con incrementos superiores a un año de educación. 


\section{Resultados econométricos}

\section{Logit bivariado}

En la Tabla 4 se presentan las medias de los efectos marginales de las variables consideradas sobre la probabilidad de ser trabajador informal con base en el modelo logit bivariado. De acuerdo con los resultados, para el 2009, ser mujer, pertenecer a hogares grandes y a hogares perceptores de rentas no laborales incrementaba la probabilidad de ser informal. En particular, ser mujer aumentaba la probabilidad de ser informal en 7,7 puntos porcentuales. Por otro lado, la edad, la escolaridad, la existencia de menores en el hogar y pertenecer a hogares uniparentales reducía dicha probabilidad. Un año adicional de educación reducía la probabilidad de ser informal en 2,9 puntos porcentuales.

Tabla 4. Resultados modelo logit. Media de los efectos marginales

\begin{tabular}{|c|c|c|}
\hline Variables & 2009 & 2019 \\
\hline Mujer & $0,077^{\star \star \star}$ & $0,077^{\star * *}$ \\
\hline Edad & $-0,078^{* * *}$ & $-0,090^{* * *}$ \\
\hline Educación & $-0,029^{* * *}$ & $-0,029^{* * *}$ \\
\hline Tamaño del hogar & $0,003^{* * *}$ & $0,006^{* * *}$ \\
\hline Niños en el hogar & $-0,011^{* * *}$ & $-0,011^{* * *}$ \\
\hline Hogar uniparental & $-0,003^{* * *}$ & $0,001^{* * *}$ \\
\hline Rentas en el hogar & $0,007^{* * *}$ & $-0,021^{* * *}$ \\
\hline
\end{tabular}

Nota: errores estándar en paréntesis. ${ }^{* * *} \mathrm{p}<0,01,{ }^{* *} \mathrm{p}<0,05,{ }^{*} \mathrm{p}<0,10$. El modelo incluye variable dummy por industria. Todas las estimaciones utilizan factores de expansión.

Para el 2019, el efecto marginal de ser mujer sobre la probabilidad de informalidad no cambia, mientras que el efecto del tamaño del hogar aumenta y el del hogar uniparental cambia de negativo a positivo. El efecto de la escolaridad y el de los niños en el hogar no varían, mientras que el de la edad aumenta en valor absoluto y el de las rentas cambia de positivo a negativo.

\section{Logit multinomial}

En la Tabla 5 se presentan los resultados econométricos del modelo logit multinomial para las diferentes posiciones ocupacionales respecto del servicio doméstico en el ámbito urbano. Los coeficientes son estadísticamente significativos y en general tienen los signos esperados. Ser mujer reduce la probabilidad de ser trabajador informal asalariado, cuenta propia, jornalero o patrón, mientras que aumenta la probabilidad de ser trabajador informal familiar o en empresas. En cuanto a la edad, incrementos en esta variable están asociados con mayores probabilidades en cuenta propia y patrones, y con menores probabilidades en asalariados, trabajadores familiares y trabajadores en empresas. La educación aumenta la 
probabilidad de ser informal en asalariado y patrón, y la reduce en cuenta propia. Este resultado contrasta con la estimación general en que el efecto marginal de la educación era negativo. En este caso, vemos que la educación tiene un efecto diferencial en las categorías ocupacionales de la informalidad. Finalmente, las rentas están asociadas a menores niveles de informalidad en asalariados y cuenta propia, y a mayores niveles en patrones.

Tabla 5. Resultados modelo logit multinomial. Media de los efectos marginales

\begin{tabular}{|c|c|c|c|c|c|c|}
\hline 2009 & $\begin{array}{l}\frac{n}{0} \\
\frac{0}{0} \\
\frac{\pi}{2} \\
\frac{\pi}{\pi} \\
\frac{\pi}{\pi} \\
\frac{0}{4}\end{array}$ & $\begin{array}{l}\frac{\pi}{2} \\
\frac{0}{0} \\
\frac{2}{2} \\
\frac{\pi}{2} \\
\frac{0}{0} \\
0 \\
0\end{array}$ & 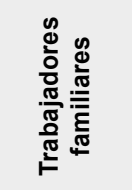 & 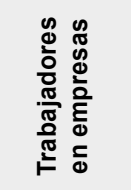 & 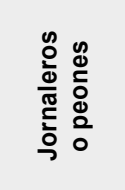 & $\begin{array}{l}\mathscr{E} \\
\stackrel{0}{0} \\
\frac{0}{5} \\
0\end{array}$ \\
\hline Mujer & $-0,062^{* * *}$ & $-0,127^{\star * \star}$ & $0,044^{* * *}$ & $0,002^{* * *}$ & $-0,006^{* * *}$ & $-0,058^{* * *}$ \\
\hline Edad & $-0,010^{* * *}$ & $0,010^{* * *}$ & $-0,010^{* * *}$ & $-0,001^{* * *}$ & $-0,000^{* * *}$ & $0,011^{* * *}$ \\
\hline Educación & $0,004^{* \star *}$ & $-0,004^{* * *}$ & $0,000^{\star * *}$ & $0,000^{* * *}$ & $-0,000^{* * *}$ & $0,010^{* * *}$ \\
\hline Tamaño del hogar & $0,000^{* * *}$ & $-0,002^{* * *}$ & $0,001^{* * *}$ & $-0,001^{* * *}$ & $-0,000^{* * *}$ & $-0,004^{* * *}$ \\
\hline Rentas & $-0,014^{* * *}$ & $-0,020^{\star * *}$ & $0,000^{* *}$ & $0,002^{\star * *}$ & $-0,000^{* * *}$ & $0,018^{* * *}$ \\
\hline \multicolumn{7}{|l|}{2019} \\
\hline Mujer & $-0,050^{* * *}$ & $-0,14^{* * *}$ & $0,035^{* * *}$ & $0,002^{* * *}$ & $-0,003^{* * *}$ & $-0,039^{* * *}$ \\
\hline Edad & $-0,009^{* * *}$ & $0,006^{* * *}$ & $-0,006^{* * *}$ & $-0,001^{* * *}$ & $-0,000^{* * *}$ & $0,006^{* * *}$ \\
\hline Educación & $0,005^{* * *}$ & $-0,006^{* * *}$ & $-0,000^{* * *}$ & $0,000^{* * *}$ & $-0,000^{* * *}$ & $0,007^{* * *}$ \\
\hline Tamaño del hogar & $0,001^{* * *}$ & $0,000 * * *$ & $0,001^{* * *}$ & $-0,000^{* * *}$ & $-0,000^{* * *}$ & $-0,005^{\star * *}$ \\
\hline Rentas & $-0,020^{* * *}$ & $-0,006^{* * *}$ & $0,007^{* * *}$ & $-0,000^{* * *}$ & $-0,001^{* * *}$ & $0,010^{* * *}$ \\
\hline
\end{tabular}

Nota: errores estándar método Delta en paréntesis. ${ }^{* * *} \mathrm{p}<0,01,{ }^{* *} \mathrm{p}<0,05$, $* \mathrm{p}<0,10$. El modelo incluye la edad al cuadrado, si el hogar tiene menores de 5 años, si el jefe de hogar no tiene compañero, e incluye variable dummy por ciudad. Todas las estimaciones utilizan factores de expansión.

En el 2019, el efecto de ser mujer continúa reduciendo la probabilidad de ser informal asalariados, cuenta propia, jornaleros y patrones, y aunque la aumenta en trabajadores familiares, esta es menor que en el 2009. Con relación a la edad, los coeficientes son menores en valor absoluto respecto del 2009. En el caso de la educación, el efecto marginal aumenta más la probabilidad de informalidad en los asalariados, la disminuye más en los cuenta propia y reduce el efecto para los patrones. Para el 2019, las rentas son más importantes para los asalariados y trabajadores familiares, y disminuyen su efecto en los cuenta propia y patrones. 


\section{Educación e informalidad en ciudades}

Con el propósito de estudiar la relación entre educación e informalidad en ciudades, en el anexo 1 y 2 se presentan los resultados de los efectos marginales estimados en ese ámbito. El anexo 1 muestra que en el 2009 la educación reduce la probabilidad de ser informal en todas las ciudades, con importantes efectos en Barranquilla, Cartagena, Pereira y Manizales, que reportan coeficientes iguales o superiores a 3,5 puntos porcentuales. Para el 2019, el efecto es alto en Cartagena, Barranquilla,
Villavicencio, Santa Marta y Montería, con efectos mayores o iguales a 3,8 puntos porcentuales. En la Figura 7 se presenta la variación absoluta de estos efectos marginales. En esta gráfica se observa que las ciudades que en el 2009 presentaban las tasas más altas de informalidad fueron las que reportaron una mayor variación en el efecto marginal de la educación que disminuyó aún más la probabilidad de ser informales. Este es un efecto positivo de la educación sobre la informalidad en el ámbito local, que podría explicar la reducción en las brechas regionales de informalidad.

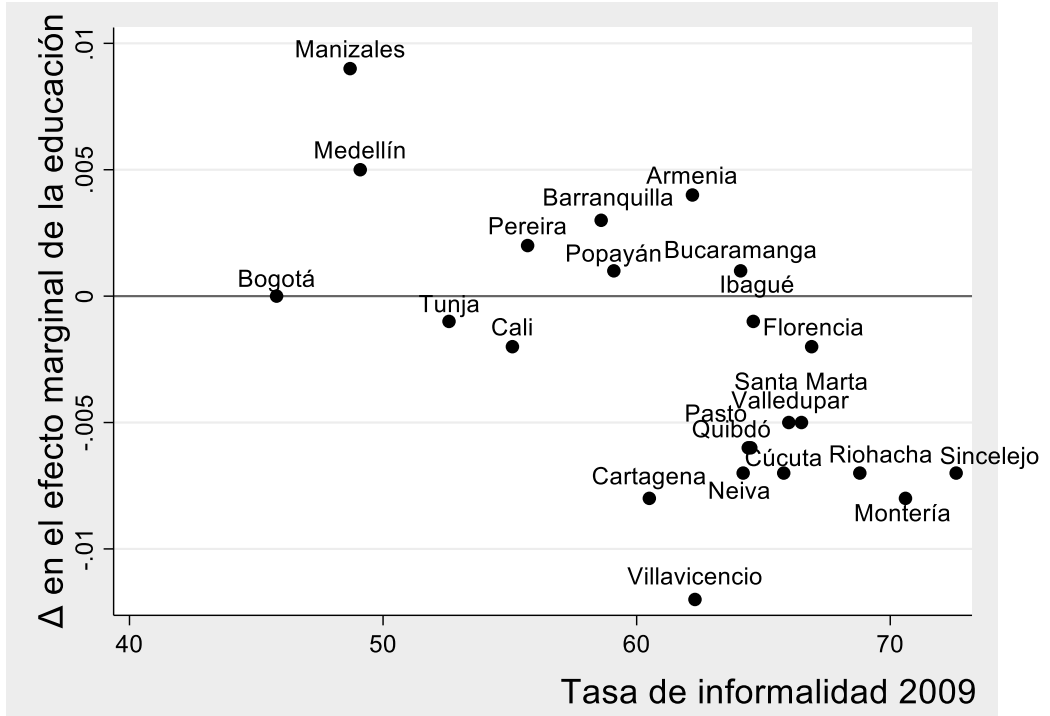

Figura 7. Variación en el efecto marginal de la educación

En el anexo 2 se presentan los efectos marginales de la educación para las categorías de asalariados y cuenta propia en ciudades. Los resultados sugieren un efecto marginal positivo en el caso de los asalariados, principalmente en Armenia y Florencia, y efectos negativos en los cuenta propia, especialmente en Armenia, Bucaramanga y Popayán. La Figura 8 presenta las variaciones 
absolutas de los coeficientes durante el periodo. En el panel izquierdo de esta figura se aprecia que el efecto positivo de la educación sobre la informalidad cae en general en el tiempo. Por su parte, en el panel derecho se observa que en ciudades como Barranquilla, Villavicencio, Neiva e Ibagué, el efecto

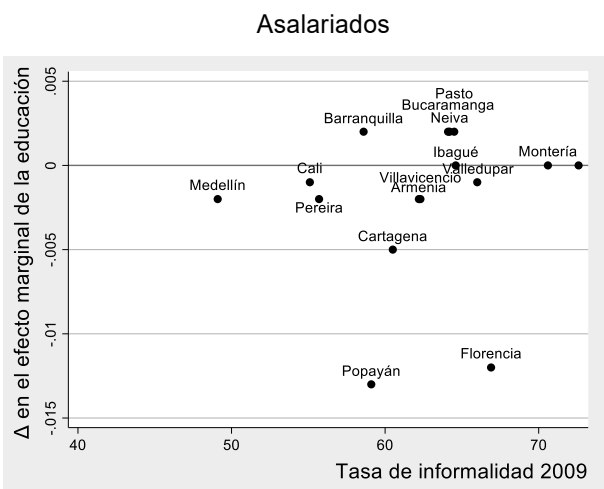

de la educación es ahora mucho más negativo, mientras que en el resto de las ciudades el efecto marginal pasa de negativo a positivo, lo que indica que, en el caso de los cuenta propia, la educación en una parte importante de las ciudades aumenta la probabilidad de ser informal.

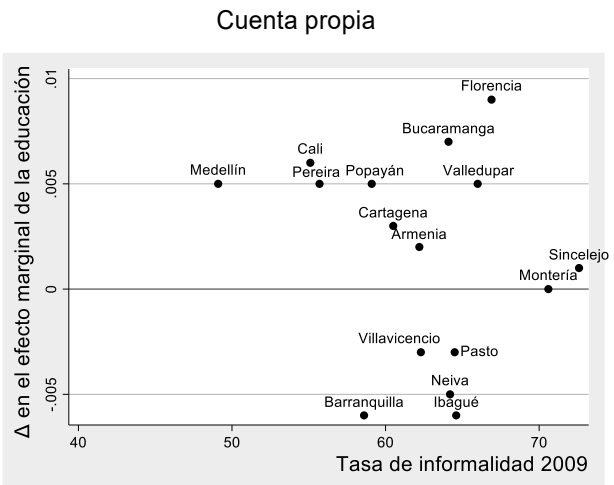

Figura 8. Variación en el efecto marginal de la educación.

\section{CONCLUSIONES}

En este documento se estudió la evolución y composición del empleo informal en Colombia a nivel nacional y por ciudades durante el periodo 2009-2019. Considerando la definición de informalidad del DANE, se analizó el empleo informal a partir de las categorías de asalariado, cuenta propia, trabajadores familiares sin remuneración, trabajadores en empresas sin remuneración, servicio doméstico, jornalero y patrones. Para estudiar los factores asociados a la condición de informalidad, se estimaron modelos logit bivariados y multinomiales considerando como variables explicativas características del individuo como género, edad, nivel educativo; características del hogar como tamaño, composición y rentas no laborales; y características de la rama de actividad económica en la que trabajan.

Los resultados indican que la tasa de informalidad a nivel nacional y por ciudades disminuyó durante el periodo estudiado, excepto para Cúcuta. Las tasas de informalidad más altas al principio del periodo se presentaban en Sincelejo, Montería y Riohacha, en donde el porcentaje de trabajadores informales superaba el $69 \%$. En contraste, en ciudades como Bogotá Manizales y Medellín dicho porcen- 
taje no alcanzaba a la mitad de sus trabajadores en el mismo año. Durante el periodo analizado, la informalidad cayó, en general, más para las ciudades que presentaron los mayores indicadores en 2009 que para ciudades que iniciaron con menores tasas. Esto se traduce en una disminución de la brecha regional, aunque en términos absolutos las diferencias en tasa de informalidad entre ciudades siguen siendo altas.

Con relación a la composición de la informalidad, los resultados sugieren que el empleo cuenta propia es la principal fuente de empleo informal en Colombia. Durante el periodo se observa una baja variabilidad en la composición del empleo informal. La caída en el nivel de informalidad a nivel nacional y la poca variabilidad en las grandes categorías de la informalidad a nivel nacional reflejaría un efecto de compensación en los indicadores de las ciudades al agregarse. En las ciudades, los factores asociados a la caída en la informalidad son heterogéneos y no siguen un patrón específico. Para algunas ciudades como Sincelejo, Florencia, Cartagena y Popayán la categoría cuenta propia fue determinante en tal reducción, mientras que en Montería, Riohacha, Ibagué, Quibdó, Villavicencio, Pereira, Tunja y Bogotá las caídas se explican más por los cambios en los grupos de asalariados, empleados domésticos y trabajadores familiares sin remuneración.
Los informales en Colombia son principalmente hombres con edad promedio de cuarenta años con menos de diez años de escolaridad, que trabajan principalmente en el comercio, la industria y el transporte. En los últimos años, tanto la edad promedio como los años de escolaridad de este grupo en general han ido aumentando. Cuando se consideran las categorías ocupacionales surgen diferencias importantes en las características sociodemográficas. En el caso del sexo, más del $57 \%$ de los asalariados, cuenta propia, jornaleros y patrones informales son hombres. Los informales con mayor edad están en los grupos de patrones, jornaleros y cuenta propia. Los mayores niveles educativos se observan en los patrones trabajadores en empresas y asalariados.

Los resultados del logit bivariado sugieren que en el 2009 ser mujer, pertenecer a hogares grandes y a hogares perceptores de rentas no laborales incrementaba la probabilidad de ser informal, mientras que la edad, la escolaridad, la existencia de menores en el hogar y pertenecer a hogares uniparentales reducía dicha probabilidad. Para el 2019, el efecto de ser mujer no varía, mientras que el efecto del tamaño del hogar aumenta y el del hogar uniparental cambia de negativo a positivo. En esta misma línea, el efecto marginal de la escolaridad y de los niños en el hogar no varía, en tanto que el de la edad aumenta en valor absoluto y el de las rentas cambia de positivo a negativo. Los efectos marginales cambian de 
signo en la medida en que se estiman modelos multinomiales que consideran las diferentes posiciones ocupacionales. Ser mujer, por ejemplo, aumenta la probabilidad de ser trabajador familiar y trabajador en empresa informal, pero la reduce en las demás categorías.

Finalmente, este artículo presenta evidencia sobre la relación entre la educación y la informalidad. Los resultados econométricos muestran que la educación en el 2009 reduce la probabilidad de ser informal en todas las ciudades, con importantes efectos en Barranquilla, Cartagena, Pereira y Manizales (efectos marginales mayores o iguales a 3,5 puntos porcentuales). Para el 2019, este efecto es mayor en Cartagena, Barranquilla, Villavicencio, Santa Marta y Montería (efectos marginales mayores o iguales a 3,8 puntos porcentuales). Al parecer, el efecto positivo de la educación sobre la informalidad a nivel local podría explicar la reducción en las brechas regionales de informalidad.

\section{CONTRIBUCIÓN DE LOS AUTORES}

Los autores contribuyeron en igual proporción a la elaboración de todas las secciones del artículo.

\section{FINANCIAMIENTO}

Este trabajo fue financiado mediante el proyecto de investigación titulado "Pobreza monetaria y multidimensional en Colombia: 2002-2015", código 160117, de la Universidad del Tolima.

\section{DECLARACIÓN CONFLICTO DE INTERESES}

Los autores declaran que no existe conflicto de intereses.

\section{AGRADECIMIENTOS}

Los autores agradecemos a los revisores anónimos por sus sugerencias, estas permitieron mejorar la calidad del manuscrito. 


\section{REFERENCIAS}

[1] Arango, L. E. \& Flórez, L. A. (2017). Informalidad laboral y elementos para un salario mínimo diferencial por regiones en Colombia. Borradores de Economía, (1023). https://www.banrep.gov.co/es/borrador-1023

[2] Arango, L. E., \& Flórez, L. A. (2021). Regional Labour Informality in Colombia and a Proposal for a Differential Minimum Wage. The Journal of Development Studies, 57(6), 1016-1037. https://doi.org/10.1080/00220388.2020.1841170

[3] Arango, L. E., Flórez, L. A., \& Guerrero, L. D. (2020). Minimum Wage Effects on Informality Across Demographic Groups in Colombia. Borradores de Economía, (1104). https://doi.org/10.32468/be.1104

[4] Ariza, J., \& Montes, G. (2017). Labour Income Inequality and the Informal Sector in Colombian cities. Cuadernos de Economía, 36(spe72), 77-98. https://doi. org/10.15446/cuad.econ.v36n72.65820

[5] Baquero, J., Londoño, D. Ortega, J., Salazar, M., Ospina V., Rodríguez, P., García, A. \& Guataquí, C. (2018). Perfil actual de la informalidad laboral en Colombia: estructura y retos. LaboUR Observatorio Laboral de la Universidad del Rosario, (6), 1-16. https://www.urosario.edu.co/Periodico-NovaEtVetera/Documentos/ Reporte-LaboUR-Informalidad-Mayo-2018-PERFIL-ACTUA.pdf

[6] Bernal, R. (2009). The Informal Labor Market in Colombia: Identification and Characterization. Desarrollo y Sociedad, (63), 145-208. https://doi.org/10.13043/ dys.63.4

[7] Berrío, J. E. \& Bran, L. (2019). Determinantes de la informalidad laboral en Colombia para el período 2008-2017. Revista CEA, 5(9). https://doi. org/10.22430/24223182.1255

[8] Bonet, J., Pérez, G. J. \& Chiriví, E. J. (2016). Informalidad laboral y en la vivienda: primeros indicios para las principales ciudades colombianas. Documentos de Trabajo sobre Economía Regional, (241). https:/www.banrep.gov.co/sites/default/ files/publicaciones/archivos/dtser_241.pdf

[9] Cameron, A. C. \& Trivedi, P. (2010). Microeconomics Using Stata. (Revised ed.). Stata Press.

[10] Canavire, G., Urrego, J. A., \& Saavedra, F. (2016). Informality and Mobility in the Labor Market: A Pseudopanel's Approach. Revista Latinoamericana de Desarrollo Económico, (27), 57-76. https://doi.org/10.35319/lajed.20162752 
[11] Departamento Administrativo Nacional de Estadística -DANE-. (2009). Metodología informalidad Gran Encuesta Integrada de Hogares GEIH. https:// www.dane.gov.co/files/investigaciones/boletines/ech/ech_informalidad/metodologia_informalidad.pdf

[12] Departamento Administrativo Nacional de Estadística -DANE-. (2020). Boletín técnico. Medición de empleo informal y seguridad social. https://www.dane.gov.co/ files/investigaciones/boletines/ech/ech_informalidad/bol_ech_informalidad_dic19_feb20.pdf

[13] Fernández, C. \& Villar, L. (2018). The Impact of Lowering the Payroll Tax on Informality in Colombia. Development Bank of Latin America, Working Papers, (2016/21). https://scioteca.caf.com/handle/123456789/1337

[14] Ferreira, M. T. (2014). Las nociones de trabajo informal y trabajo precario en el análisis de la calidad del empleo en Colombia. Revista Lebret, (6), 29-58. https:// doi.org/10.15332/rl.v0i6.1449

[15] Galvis, L. A. (2013). Informalidad laboral en las áreas urbanas de Colombia. Documentos de Trabajo sobre Economía Regional y Urbana, (164). https://www. banrep.gov.co/es/dtser-164

[16] Galvis, L. A. \& Pérez, G. J. (2015). Informalidad laboral y calidad del empleo en la región Pacífica colombiana. Documentos de Trabajo sobre Economía Regional y Urbana, (233). https://www.banrep.gov.co/sites/default/files/publicaciones/archivos/dtser_233.pdf

[17] Galvis, L. A., Rodríguez, G. O. \& Ovallos, S. (2019). Desempleo y calidad de vida laboral en las áreas metropolitanas de Barranquilla, Cartagena y Santa Marta. Documento de Trabajo sobre Economía Regional y Urbana, (279). https://www. banrep.gov.co/es/desempleo-y-calidad-vida-laboral-las-areas-metropolitanas-barranquilla-cartagena-y-santa-marta

[18] García, G. A. (2008). Informalidad regional en Colombia. Evidencia y determinantes. Revista Desarrollo y Sociedad, (61), 43-86. https://doi.org/10.13043/dys.61.2

[19] García, G.A. (2017). Labor Informality: Choice or Sign of Segmentation? A Quantile Regression Approach at the Regional Level for Colombia. Review of Development Economics, 21(4), 985-1017. https://doi.org/10.1111/rode.12317

[20] Guataquí, J. C., García, A. F. \& Rodríguez, M. (2010). El perfil de la informalidad laboral en Colombia. Perfil de Coyuntura Económica, (16), 91-115. 
[21] Habib-Mintz, N. (2009). To What Extent Can the Informal Economy Concept Adequately Explain the Dynamism of the Non-Formal Sector in Developing Countries? Journal of International Business and Economy, 10(1), 1-19. https://doi. org/10.51240/jibe.2009.1.1

[22] Hamann, F. A., \& Mejía, L. F. (2011, oct.). Formalizando la informalidad empresarial en Colombia. Borradores de Economía, (676). https://www.banrep.gov.co/ es/node/25547

[23] Herrera, P., Garlati, P. \& Torres, T. (2019). Getting Over the Minimum Wage: Wage Gaps Between Cities in Colombia. Pontificia Universidad Javeriana. https://sistemas.colmex.mx/Reportes/LACEALAMES/LACEA-LAMES2019_paper_125.pdf

[24] Mejía, D. \& Posada, C. E. (2007). Informalidad: teoría e implicaciones de política. Borradores de Economía, (455). https://doi.org/10.32468/be.455

[25] Mora, J. J. (2017). La informalidad laboral colombiana en los últimos años: análisis y perspectivas de política pública. Revista de Métodos Cuantitativos para la Economía y la Empresa, 24, 89-128.

[26] Organización Internacional del Trabajo -OIT-. (2002). Effect to be given to resolutions adopted by the International Labour Conference at its 90th Session (2002), (b) Resolution concerning decent work and the informal economy. OIT.

[27] Organización Internacional del Trabajo -OIT-. (2013). La medición de la informalidad: Manual estadístico sobre el sector informal. https://www.ilo.org/ wcmsp5/groups/public/---dgreports/---dcomm/---publ/documents/publication/ wcms_222986.pdf

[28] Organización Internacional del Trabajo -OIT-. (2019). Panorama laboral 2019. América Latina y el Caribe. https:/www.ilo.org/wcmsp5/groups/public/---americas/---ro-lima/documents/publication/wcms_732198.pdf

[29] Quejada, R., Yánez, M. \& Cano, K. (2014). Determinantes de la informalidad laboral: un análisis para Colombia. Investigación \& desarrollo, 22(1), 126-145. http://dx.doi.org/10.14482/indes.22.1.3078

[30] Ramírez, M. T. (2015). La informalidad en el mercado laboral colombiano. Reportes del Emisor, (197). Recuperado de: https://www.banrep.gov.co/es/ emisor-197 
[31] Romero, A. M. (2013). Informalidad laboral en los centros urbanos de Colombia: ¿depende del desplazamiento forzado? Universidad Javeriana. https://cea.javeriana.edu.co/documents/153049/2786252/Vol.13_4_2013. pdf/1cb09d9b-4d67-402b-8f65-1f32fcec44e7

[32] Salcedo, C., Moscoso, F. \& Ramírez, M. (2020). Economía informal en Colombia: iniciativas y propuestas para reducir su tamaño. Revista Espacios, 41(03), 22-29.

[33] Salinas, J. D., González, S. I. \& Marín, L. J. (2012). Características de la población ocupada en Colombia: un análisis del perfil de los formales e informales. Perfil de Coyuntura Económica, 20, 57-86.

[34] The World Bank (2010). Informality in Colombia. Implications for Worker Welfare and Firm Productivity. Document of the World Bank, (42698CO). http://documents.worldbank.org/curated/en/385321468243561833/ Informality-in-Colombia-implications-for-worker-welfare-and-firm-productivity

[35] Uribe, J. I., Ortiz, C. H. \& Castro, J. A. (2006). Una teoría general sobre la informalidad laboral: el caso colombiano. Economía y Desarrollo, 5(2), 213-273.

[36] Yusuff, O. (2011). A Theoretical Analysis of The Concept of Informal Economy and Informality in Developing Countries. European Journal of Sciences, 20(4), 624-636. 
Anexo 1. Promedio de los efectos marginales de la educación sobre la probabilidad de ser informal

\begin{tabular}{|c|c|c|}
\hline Ciudad & 2009 & 2019 \\
\hline Bogotá & $-0,030^{* * *}$ & $-0,030^{* * *}$ \\
\hline Medellín & $-0,033^{* * *}$ & $-0,028^{* * *}$ \\
\hline Barranquilla & $-0,042^{* * *}$ & $-0,039^{* * *}$ \\
\hline Cartagena & $-0,040^{* * *}$ & $-0,048^{* * *}$ \\
\hline Manizales & $-0,034^{* * *}$ & $-0,025^{\star * *}$ \\
\hline Montería & $-0,030^{* * *}$ & $-0,038^{* * *}$ \\
\hline Villavicencio & $-0,027^{* * *}$ & $-0,039^{* * *}$ \\
\hline Pasto & $-0,028^{* * *}$ & $-0,034^{* * *}$ \\
\hline Cúcuta & $-0,023^{* * *}$ & $-0,030^{* * *}$ \\
\hline Pereira & $-0,035^{* * *}$ & $-0,033^{* * *}$ \\
\hline Bucaramanga & $-0,033^{* * *}$ & $-0,032^{* * *}$ \\
\hline Ibagué & $-0,032^{* * *}$ & $-0,033^{* * *}$ \\
\hline Cali & $-0,031^{* * *}$ & $-0,033^{* * *}$ \\
\hline Armenia & $-0,033^{* * *}$ & $-0,029^{* * *}$ \\
\hline Tunja & $-0,023^{* * *}$ & $-0,024^{* * *}$ \\
\hline Florencia & $-0,021^{* * *}$ & $-0,023^{* * *}$ \\
\hline Popayán & $-0,030^{* * *}$ & $-0,029 * * *$ \\
\hline Valledupar & $-0,028^{* * *}$ & $-0,033^{* * *}$ \\
\hline Quibdó & $-0,016^{* * *}$ & $-0,022^{* * *}$ \\
\hline Neiva & $-0,028^{* * *}$ & $-0,035^{\star * *}$ \\
\hline Riohacha & $-0,019^{* * *}$ & $-0,026^{* * *}$ \\
\hline Santa Marta & $-0,033^{* * *}$ & $-0,038^{* * *}$ \\
\hline Sincelejo & $-0,023^{* * *}$ & $-0,030^{* * *}$ \\
\hline
\end{tabular}

Nota: errores estándar en paréntesis. $* * * \mathrm{p}<0,01, * * \mathrm{p}<0,05, * \mathrm{p}<0,10$. El modelo incluye el género, la edad, la edad al cuadrado, el número de integrantes del hogar, si el hogar tiene menores de 5 años, si el jefe de hogar no tiene compañero y si el hogar tiene ingresos no laborales. Se controla además por rama de actividad económica. Todas las estimaciones utilizan factores de expansión 
Anexo 2. Promedio de los efectos marginales de la educación sobre la probabilidad de ser informal en asalariados y cuenta propia. Modelo logit multinomial

\begin{tabular}{|c|c|c|c|c|}
\hline \multirow[b]{2}{*}{ Ciudad } & \multicolumn{2}{|c|}{ Asalariados } & \multicolumn{2}{|c|}{ Cuenta propia } \\
\hline & 2009 & 2019 & 2009 & 2019 \\
\hline Bogotá & $0,002^{* * *}$ & & $0,001^{* * *}$ & \\
\hline Medellín & $0,007^{* * *}$ & $0,005^{* * *}$ & $-0,01^{* * *}$ & $-0,005^{* * *}$ \\
\hline Barranquilla & $0,006^{* * *}$ & $0,008^{* * *}$ & $-0,003^{* * *}$ & $-0,009^{* * *}$ \\
\hline Cartagena & $0,007^{* * *}$ & $0,002^{* * *}$ & $-0,003^{* * *}$ & $0,000^{* * *}$ \\
\hline Manizales & $0,007^{* * *}$ & & $-0,011^{* * *}$ & \\
\hline Montería & $0,004^{* * *}$ & $0,004^{* * *}$ & $0,001^{* * *}$ & $0,001^{* * *}$ \\
\hline Villavicencio & $0,004^{* * *}$ & $0,002^{* * *}$ & $-0,005^{\star * *}$ & $-0,008^{* * *}$ \\
\hline Pasto & $0,006^{* * *}$ & $0,008^{* * *}$ & $-0,011^{* * *}$ & $-0,014^{* * *}$ \\
\hline Cúcuta & $0,003^{* * *}$ & & $-0,005^{* * *}$ & \\
\hline Pereira & $0,008^{* * *}$ & $0,006^{* * *}$ & $-0,004^{* * *}$ & $0,001^{* * *}$ \\
\hline Bucaramanga & $0,006^{* * *}$ & $0,008^{* * *}$ & $-0,014^{* * *}$ & $-0,007^{* * *}$ \\
\hline Ibagué & $0,000^{* * *}$ & $0,000^{* * *}$ & $0,000^{* * *}$ & $-0,006^{* * *}$ \\
\hline Cali & $0,001^{* * *}$ & $0,000^{* * *}$ & $-0,005^{\star \star *}$ & $0,001^{* * *}$ \\
\hline Armenia & $0,012^{* * *}$ & $0,01^{* * *}$ & $-0,015^{\star \star *}$ & $-0,013^{* * *}$ \\
\hline Tunja & $-0,002^{* * *}$ & & $-0,003^{\star * *}$ & \\
\hline Florencia & $0,012^{* * *}$ & $0,000^{* * *}$ & $-0,009^{* * *}$ & $0,000^{* * *}$ \\
\hline Popayán & $0,006^{* * *}$ & $-0,007^{\star * *}$ & $-0,012^{* * *}$ & $-0,007^{* * *}$ \\
\hline Valledupar & $0,008^{* * *}$ & $0,007^{* * *}$ & $-0,009^{* * *}$ & $-0,004^{* * *}$ \\
\hline \multicolumn{5}{|l|}{ Quibdó } \\
\hline Neiva & $0,005^{* * *}$ & $0,007^{* * *}$ & $-0,008^{* * *}$ & $-0,013^{* * *}$ \\
\hline Riohacha & $0,007^{* * *}$ & & $-0,008^{\star * *}$ & \\
\hline Santa Marta & & $0,008^{* * *}$ & & $-0,007^{* * *}$ \\
\hline Sincelejo & $0,009^{* * *}$ & $0,009^{* * *}$ & $-0,008^{* * *}$ & $-0,007^{* * *}$ \\
\hline
\end{tabular}

Nota: errores estándar en paréntesis. $* * * \mathrm{p}<0,01, * * \mathrm{p}<0,05, * \mathrm{p}<0,10$. El modelo incluye el género, la edad, la edad al cuadrado, el número de integrantes del hogar, si el hogar tiene menores de 5 años, si el jefe de hogar no tiene compañero y si el hogar tiene ingresos no laborales. Se controla además por rama de actividad económica. Todas las estimaciones utilizan factores de expansión. Solo se presentan estimaciones de efectos marginales en los casos en los que se alcanzó convergencia. 